\title{
Benchmarking the Higher Education Institutions in Egypt using Composite Index Model
}

\author{
Mohamed Rashad M El-Hefnawy \\ Computer Engineering Department \\ Arab Academy for Science \& \\ Technology Cairo, Egypt
}

\author{
Ali Hamed El-Bastawissy \\ Computer Science Department \\ Modern Sciences and Arts \\ University Cairo, Egypt
}

\author{
Mona Ahmed Kadry \\ Computer Science Department \\ Arab Academy for Science \& \\ Technology Cairo, Egypt
}

\begin{abstract}
Egypt has the largest and most significant higher education system in the Middle East and North Africa but it had been continuously facing serious and accumulated challenges. The Higher Education Institutions in Egypt are undergoing important changes involving the development of performance, they are implementing strategies to enhance the overall performance of their universities using ICT, but still the gap between what is existing and what is supposed to be for the selfregulation and improvement processes is not entirely clear to face these challenges. The using of strategic comparative analysis model and tools to evaluate the current and future states will affect the overall performance of universities and shape new paradigms in development of Higher Education System (HES), several studies have investigated the evaluation of universities through the development and use of ranking and benchmark systems
\end{abstract}

In this paper, we provide a model to construct unified Composite Index (CI) based on a set of SMART indictors emulate the nature of higher education systems in Egypt. The outcomes of the proposed model aim to measure overall performance of universities and provide unified benchmarking method in this context. The model was discussed from theoretical and technical perspectives. Meanwhile, the research study was conducted with 40 professors from 19 renowned universities in Egypt as education domain experts.

Keywords-Key Performance Indicators; Composite Index; Analytic Hierarchy Process; Performance Measurement; Higher Education Institutions; Ranking Systems; Benchmark Models

\section{INTRODUCTION}

Egypt has the largest education system in the Middle East and North Africa and it has grown rapidly since the early nineties, according to the Human Development Index (HDI) 2013 report, Egypt is ranked 121 in the HDI, and number 7 in the Medium HDI countries in Africa [1]. The higher education system in Egypt has around 2,646 million students were enrolled across all tertiary levels. They attended one of 24 public universities, including Al-Azhar University, the oldest continuously running university in the world; 18 private universities including non-for-profit Nile University; 3 private Academies; 58 public non-university institutions and 137 private higher or middle institutes, as shown in Table I. Nonuniversity institutions are middle technical institutes offering two-year courses and higher technical institutes offering fouryear courses. Since 25 January revolution, seven new universities have been created. Based on strategic plan of Supreme Council of Universities (SCU) in Egypt [2], about
4,771 million students are expected to enroll in 2021 across all tertiary levels.

TABLE I. FACTS ABOUT HighER EDUCATION SYSTEM IN EGYPT

\begin{tabular}{|c|c|c|c|c|}
\hline \multicolumn{7}{|c|}{$\begin{array}{c}\text { Number of Iat } \\
\text { (in academic year 2012/2013) }\end{array}$} \\
\hline Public & Private & $\begin{array}{c}\text { Privase } \\
\text { Academies }\end{array}$ & $\begin{array}{c}\text { Public non- } \\
\text { university } \\
\text { institutions }\end{array}$ & $\begin{array}{c}\text { Private higher } \\
\text { of middle } \\
\text { institutes }\end{array}$ \\
\hline 24 & 18 & 3 & 58 & 137 \\
\hline \multicolumn{6}{|c|}{ Number of students } \\
(In academic year 2012/2013)
\end{tabular}

The Ministry of Higher Education supervises the tertiary level of education and in order to improve the quality of a university services, it has established a committee for the reform of higher education known as the Higher Education Enhancement Project (HEEP) committee. Higher education reform strategy included 25 projects addressing all the reform domains up to our knowledge till 2017, the most important project know as Information and Communications Technology Project (ICTP). This project adopted a service category stakeholder approach to quantify the ICT needs of academic institutes [3]. The services include IT infrastructure improvement and provide integrated network infrastructure between all universities; implementing unified Management Information System (MIS) [4] and Decision Support System (DSS) as administrative computing systems for each university and technical institute; implementing a web portal for each university; establishing a union catalogue index for the university libraries; training employees and staff members on IT usage; implementing unified eLearning solution and providing access to digital libraries and federated search tools to Egyptian scholars . Each higher education institute has all of the above services and resources, which has a well overall impact on performance of the higher education institute. Otherwise, no single university, however large, can encompass all knowledge. Every university has to make choices. It is demanding to be world-class university [5] in even a few academic area. Each university has to priorities the use of its resources and use them to improve overall performance and increase service quality. Knowing whether it is succeeding in its aims is another more demanding level of difficulty. The key challenging question is how universities' leaders will 
know where their institutions stand and how they can be improved [6,7]. The gap between what is existing and what is supposed to be for the self-evaluation and improvement processes is not entirely clear. For that, the comparative experiences from other universities may help shed the light on possible solutions to provide both strengths and weaknesses in the present strategic context.

In the literature, the methodology of university ranking has gained a considerable importance among higher education institutions $[8,12]$, a fair view can usually be drawn from the outcomes of indicators [9]. Common stakeholders in higher education, decision makers and researchers are definitely keen to know the position of the institutions and figure out the key reasons behind ranking results and outcomes to improve strategic planning, reviewing overall performance, improve operations, change management, compare performance with comparable institutions or with "best practices" benchmarks and to assist their institutions in evaluation, decision making, and improvement processes [10, 23].

This paper provides theoretical and technical framework as a benchmark for measuring the overall performance of higher education institutions in Egypt .The proposed model creates a mixed criteria Composite Index (CI) relative to a set of weighted and aggregated Key Performance Indicators (KPI), illustrated in a scientific manner. Attention is focused on using Analytic Hierarchy Process (AHP) to weight and aggregate $[29,11]$ the indicators used by the proposed composite index.

This paper is structured as follows: Section 2 describes the related work. Section 3 describes the used analysis method .The use of the method is illustrated by a case study in Section 4. Section 5 demonstrates experimental results. Section 6 presents conclusions and suggestions for future work.

\section{RELATED WORK}

\section{A. Ranking Systems}

There are about 50 ranking systems in use around the world which use several of different key performance indicators. Several academic institutions, media organizations, governmental or non- governmental agencies [10] have already conducted ranking methodology on global, regional and national bases for higher education systems. The countries, which conduct rankings of universities, departments or programs, include Australia, Canada, China, Hong Kong, India, Spain, UK, US, etc. These countries have diverse systems of ranking based on different criteria covering indicators related to students, faculty, research publications, research funding and grants, alumni donations, graduation rates, social mobility, ethics of service to country, peers, finances, infrastructure, and reputation. These indicators broadly fall into seven subjects, student outcomes, financial inputs and outcomes, and staff outcomes, student experiences, learning and teaching outcomes, research outcomes and reputation [12]. The most famous ranking systems, Shanghai Academic ranking of world Universities (ARWU); Times Higher Education world university ranking (THE-QS); Webometrics ranking of world Universities; Taiwan Higher Education Accreditation and Evaluation Council (HEEACT).
The scope of world ranking systems are generic and do not focus on issues on issues related to region or local strategies, which may lead the decision maker to reform strategies based on ranking improvement for other countries rather than to do the right for the local setting. In general, the presence of Egyptian universities in global ranking systems is not bad, but this does not mean that Egyptian universities use these rates to improve their performance compared with others standard and leaders universities. The focus on the ranking systems results dispatch resources utilization away from success improvement factors related to certain issues because there are no criteria that measure those. In this paper, we focus on set of KPIs that are related to Egypt country strategy for higher education system.

\section{B. Analytic Hierarchy Process (AHP)}

As data analysis method, AHP was used in the study. AHP was firstly put forward in 1968s by Myers and Alpert and was developed and transformed to a usable model in resolutions of deciding problems as analytical techniques for complex decision making problems by Saaty in 1977s [13, 22]. In AHP method, quantitative values like price, weight, or area, or even subjective opinions or qualitative items such as feelings, preferences, or satisfaction, can be translated into measurable numeric relations. AHP belongs to the multi-criteria decision making methods (MCDM) group, an estimation method that is used in cases in which a decision hierarchy is present and that interpret per cent distributions of decisions points, in terms of factors affecting the decision. AHP on a decision hierarchy, is based on pairwise comparisons to determine significance values of decision points, in terms of the factors that affect the decision using a comparison scale identified beforehand. Significance differences, ultimately, turn into per cent distributions on decision points. AHP has been used in fields of higher education such as scientific analysis, ranking and evaluation systems [14, 15, 16, and 24].

Practice process of AHP consists of five steps. In creation of hierarchy, the first step, the purpose of AHP method usage is defined and the hierarchical structure related to the purpose is set forth (Wind and Saaty, 1980) and reflect the relationship between the purpose of the comparison and the result that is desired to be obtained. The hierarchical structure includes main and short-listed sub-criteria containing the decision goal. The second step is the arrangement of binary comparison matrixes in which main or sub-criteria are compared with alternatives between each other. While the mutual comparison of the factors are done, the evaluation scale recommended by Saaty (1994) defined in Table II is used. This scale consists of importance scales that are defined from1 to 9. A criterion which is compared with itself, is always assigned the value 1, so the main diagonal entries of the pairwise comparison matrix are all 1 . The numbers $3,5,7$, and 9 correspond to the verbal judgments 'moderate importance', 'strong importance', 'very strong importance', and 'absolute importance' (with 2, 4, 6, and 8 for compromise between the previous values). Every two factors are enumerated mutually with one of these numbers. While creating comparison matrices, it is questioned on how much important the factor on the row when compared the one on the column. The intermediate values are the values that can be chosen by the decision maker if he is in dilemma 
between two main values. If criterion $A$, is of stronger importance than that of criterion $B$ then the comparative value 7 is given, if they have equal importance then the comparative value 1 is given. In this case, the criterion B takes the value $1 / 7$ or 1 when compared to A. Because the reverse of the same criteria are the reverse of the same point according to multiplication. The third step of AHP is the creation of normalized matrixes and the occurrence of each factor's significance level. The fourth step of the method is the determination of the fact that whether the matrixes are consistent or not; the fifth step and the last stage, on the other hand, is the assignation of priorities. These five steps belonging to AHP method were followed through, elaborated calculations and equations discussed in the following section.

TABLE II. AHP SCALE FOR PAIRWISE COMPARISONS

\begin{tabular}{|c|l|l|}
\hline \multicolumn{3}{|c|}{ The Fundamental Scale for Pairwise Comparisons } \\
\hline $\begin{array}{c}\text { Intensity of } \\
\text { Importance }\end{array}$ & \multicolumn{1}{|c|}{ Definition } & \multicolumn{1}{c|}{ Explanation } \\
\hline 1 & Equal importance & $\begin{array}{l}\text { Two elements contribute equally to the } \\
\text { objective }\end{array}$ \\
\hline 3 & Moderate importance & $\begin{array}{l}\text { Experience and judgment moderately } \\
\text { favor one element over another }\end{array}$ \\
\hline 5 & Strong importance & $\begin{array}{l}\text { Experience and judgment strongly favor } \\
\text { one element over another }\end{array}$ \\
\hline 7 & Very strong importance & $\begin{array}{l}\text { One element is favored very strongly } \\
\text { over another, its dominance is } \\
\text { demonstrated in practice }\end{array}$ \\
\hline 9 & Extreme importance & $\begin{array}{l}\text { The evidence favoring one element } \\
\text { over another is of the highest possible } \\
\text { order of affirmation }\end{array}$ \\
\hline
\end{tabular}

Intensities of 2, 4, 6, and 8 can be used to express intermediate values. Intensities of $1.1,1.2,1.3$, etc. can be used for elements that are very close in importance.

\section{Composite Indicators}

Generally, a composite indicator is formed when individual indicators are compiled into a single index on the basis of an underlying model. It is tailored wide-model for benchmark simulation and comparative analysis purposes, comparisons can be used to illustrate complex and elusive issues in wide-ranging fields, e.g., environment, economy, society or technological development. Steps followed to construct any composite index are listed as follows, (1) theoretical and conceptual framework should be developed to provide the basis for the selection and combination of single indicators into a meaningful composite indicator under a fitness-for-purpose principle; (2) indicators should be selected on the basis of their analytical soundness, measurability, relevance to the phenomenon being measured and relationship to each other; (3) consideration should be given to different approaches for imputing missing values; (4) exploratory analysis should investigate the overall structure of the indicators, assess the suitability of the data set and explain the methodological choices like weighting, aggregation; (5) indicators should be normalized to render them comparable; (6) indicators should be aggregated and weighted according to the underlying theoretical framework; (7) analysis should be undertaken to assess the robustness of the composite indicator in terms; (8) testing should be applied in the real data; (9) attempts should be made to correlate the composite indicator with other published indicators, as well as to identify linkages through regressions; and (10) composite indicators can be visualized or presented in a number of different ways, which can influence their interpretation. Indeed, general public easily can analyze composite index outcomes than identifying common trends across detailed indicators [17]. Bandura in 2006 considered an inventory of 165 composite indexes in the development space [18].

\section{ANALYSIS METHOD}

In order not to sever the ties with the main theme of the study, findings related to demographic features, theoretical framework development, data selection, rehearse meetings and multivariate analysis steps with the ICTP professors as education experts have not been discussed here in detailed, also others points related to survey design methodology over data collection up to reliability and validity in practical testing are not discussed.

There are several techniques based on Multi-Criteria Decision Analysis (MCDA), we have selected the popular Analytic Hierarchy Process (AHP) this techniques support decision making through "Pairwise Comparisons" which uses comparison between pairs to build our weighted composite index. The block diagram in Fig.1 show the methodology used to collect responses from domain experts. The survey website populated the history database with records. Microsoft SQL Server stored procedures are invoked by an admin module to execute AHP algorithms then display the results to decision makers. In the algorithms, the priorities are calculated using the row geometric mean method (RGMM) [26], either aggregation of individual priorities (AIP) for individual participants, or an aggregation of individual judgments (AIJ) [25] based on the weighted geometric mean method (WGMM) of all participants' judgments can calculated, alerts and notifications for judgment exceed level of consistency are implemented. The consistency ratio (CR) and the geometric consistency index (GCI) are calculated. The judgment matrix, normalized principal Eigen vector and ranking of priorities are visualized in dashboard as presentation layer.

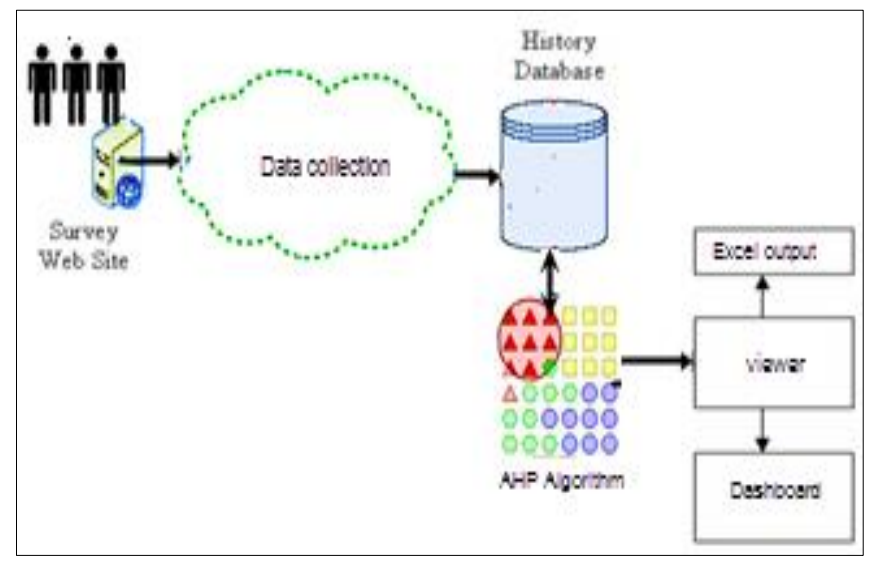

Fig. 1. Block diagram of the proposed system

\section{CASE STUDY}

\section{A. Constructing the Compsite Index}

As discussed earlier, there are steps followed to construct the composite index, these steps has categorized and grouped into four phases as shown in Fig.2 phase one present the techniques used to develop the theoretical and conceptual 
framework, using these topics (1) Theoretical framework; and (2) Data selection.

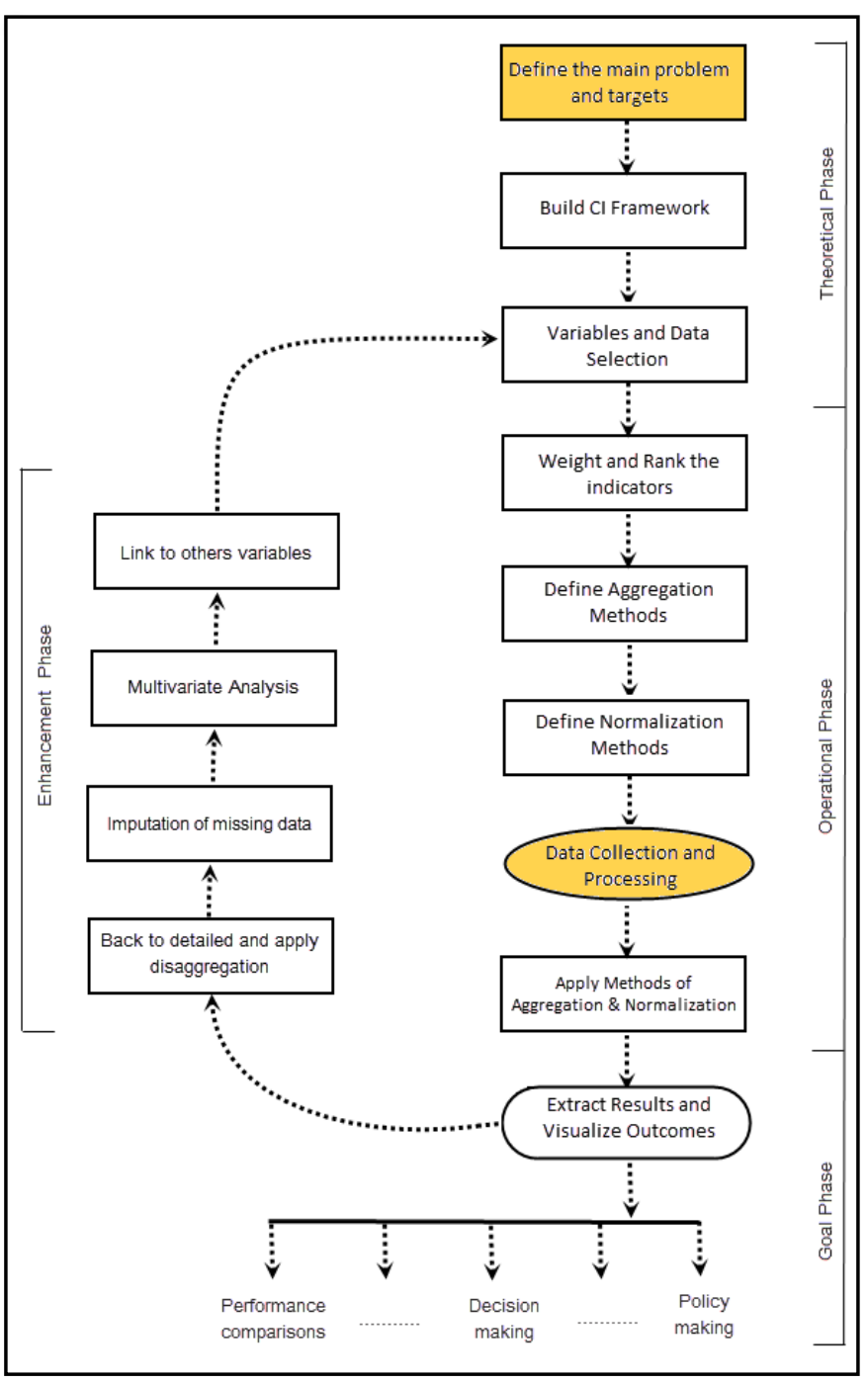

Phase two present the operation and calculation methods used to build the proposed composite Index, based-on (3) Weighting and aggregation methods; (4) Normalization methods; and (5) Consistency and Uncertainty Analysis. Phase three focus on the results extraction, using (6) Presentation and Visualization techniques. Phase four focus on the mechanisms used to enhance the outcomes of composite Index after the dissemination stage, based-on (7) Back to details on the real data; (8) Links to other variables; (9) Imputation of missing data; and (10) Multivariate analysis; Meanwhile, the steps listed regarding phase four postponed as feature work.

\section{B. The Theoretical Framework and Variables Selection}

The first stage of case study implementation, hierarchy, has been generated and shown in Fig.3, which is basically composed by three levels: the goals, the main-criteria (KPIs' Areas), the sub-criteria (set of KPIs under each area) and the alternatives that used to achieve the research target.

The key performance indicators were discussed and ascertained by the education experts and these indicators were classified on the basis of business functions, each KPI has been carefully selected according to the global standard of higher education benchmark and belong to the Egyptian situation. Moreover, the KPIs follow the SMART criteria.

This means the measure has a specific purpose for the business, it is measurable to really get a value of the KPI, the defined norms have to be achievable, the improvement of a KPI has to be Relevant to the success of the organization, and finally it must be time bound, which means the value or outcomes are shown for a predefined and relevant period. The definitions of the indicators concerning the codes and main area illustrated in Table III.

Fig. 2. Life-cycle of proposed Composite Index

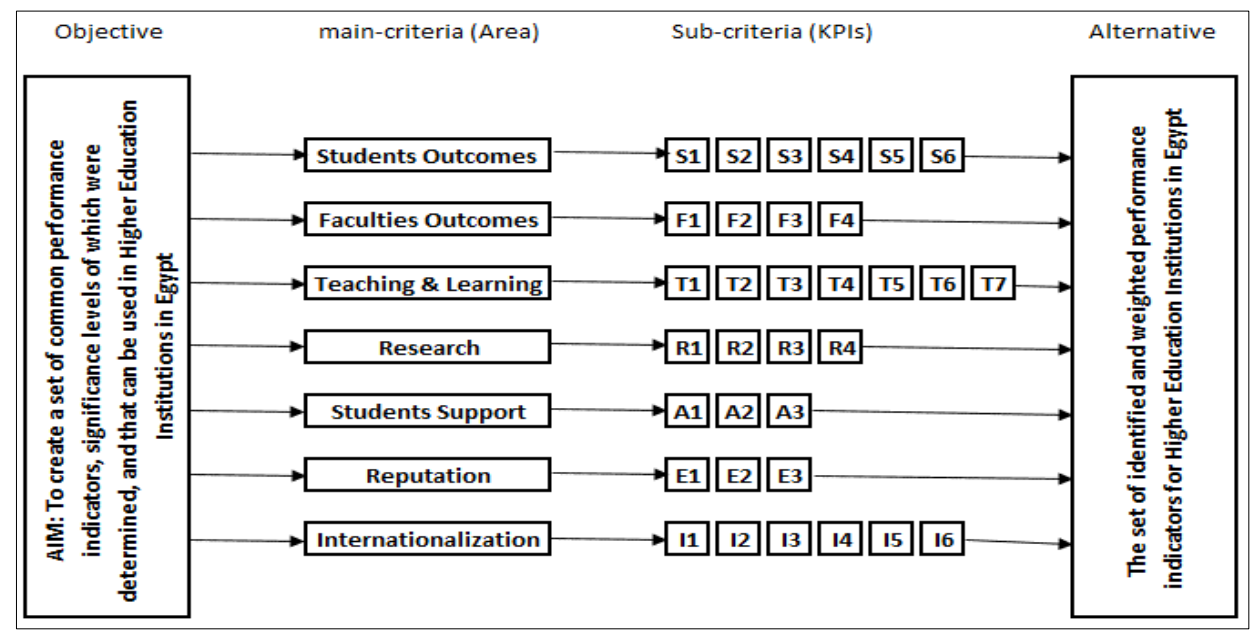

Fig. 3. Hierarchic structure of the problem 
TABLE III. HIERARCHICAL STRUCTURE OF THE PROBLEM

\begin{tabular}{|c|c|c|c|}
\hline Area & Code & Indicator & Description \\
\hline \multirow{6}{*}{ 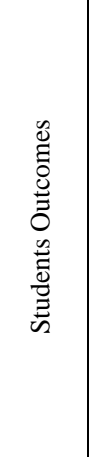 } & S1 & $\begin{array}{l}\begin{array}{l}\text { Overall Student } \\
\text { (Survey) }\end{array} \\
\end{array}$ & Proportion of students expressing satisfaction with overall experience in student survey \\
\hline & $\mathrm{S} 2$ & Completion & Proportion of students scheduled to graduate succeeding in doing so (undergraduate - postgraduate ) \\
\hline & S3 & Retention rate & $\begin{array}{l}\text { Percentage of first-time freshmen students who return for the fall of the following year (dropout after one } \\
\text { year \& two year ) }\end{array}$ \\
\hline & S4 & Granted Degrees & Number of degrees granted to students (Master-Doctoral) \\
\hline & S5 & participation & Percentage of students trained in public or private sectors annually \\
\hline & S6 & Scholarships and bursaries & Number of students receiving Honors Scholarship \\
\hline \multirow{4}{*}{ 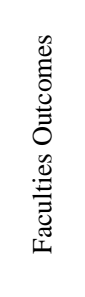 } & F1 & Faculty qualifications & $\begin{array}{l}\text { proportion of academic faculty with earned doctorates to be equivalent to international proportions against } \\
\text { number of junior staff }\end{array}$ \\
\hline & $\mathrm{F} 2$ & Attainment & Number of full-time faculty (teaching and administrative) with Offered degrees \\
\hline & F3 & Publications & Number of annual publications by faculty \\
\hline & F4 & Efficiency & Number of faculty engaged in international research activities \\
\hline \multirow{7}{*}{ 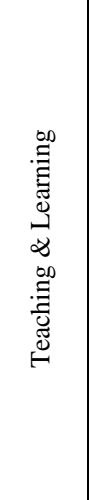 } & T1 & Faculty to student ratio & The ratio of full-time faculty to full-time students \\
\hline & $\mathrm{T} 2$ & $\begin{array}{l}\text { Faculty to Administrative staff } \\
\text { ratio }\end{array}$ & The ratio of full-time faculty to Administrative staff ratio \\
\hline & T3 & $\begin{array}{l}\text { Satisfaction with teaching } \\
\text { (Survey) }\end{array}$ & $\begin{array}{l}\text { Proportion of students expressing satisfaction with teaching through student survey (Teaching Methodology, } \\
\text { Staff, Courses) }\end{array}$ \\
\hline & $\mathrm{T} 4$ & Further study & Proportion of students pursuing further study within 12 months of graduation \\
\hline & T5 & Gender balance & The ratio of recognition of gender parity \\
\hline & T6 & Graduate employment rate & Percentage of alumni reporting being employed 24 months after graduation \\
\hline & $\mathrm{T} 7$ & Continuous improvement & Number of new programs offered by university \\
\hline \multirow{4}{*}{ 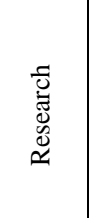 } & R1 & Citations per paper & Normalized average citations per paper \\
\hline & $\mathrm{R} 2$ & Papers per faculty & Average of research papers per faculty \\
\hline & R3 & Research excellence \& outputs & Number of cited papers or articles in high impact journals \\
\hline & $\mathrm{R} 4$ & Research funding & Average Amount of postgraduate students from university budget of research \\
\hline \multirow{3}{*}{ 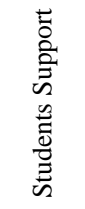 } & A1 & Environmental impact (Survey) & Performance against a Survey of environmental indicators \\
\hline & A2 & Low-income outreach & Proportion of students identified as low-income OR investment in promotion to low-income families \\
\hline & A3 & Internal migration & Proportion of overseas students from other governorates and non-foreign \\
\hline \multirow{3}{*}{ 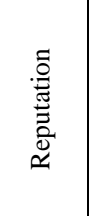 } & E1 & International outlook & Number of ranking performance in specific disciplines or overall in one of international Ranking system \\
\hline & $\mathrm{E} 2$ & Distinguished Alumni & Number of Alumni whom listed in distinguished list \\
\hline & E3 & Prolific academic experts & $\begin{array}{l}\text { Number of faculty members or Alumni achieving international recognition through awards (e.g. Nobel } \\
\text { Laureates or Fields Medalists) }\end{array}$ \\
\hline \multirow{2}{*}{ 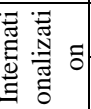 } & I1 & International faculty & Proportion of international faculty \\
\hline & $\mathrm{I} 2$ & Visiting scholars & Number of visiting professors from international universities \\
\hline
\end{tabular}


(IJACSA) International Journal of Advanced Computer Science and Applications, Special Issue on Extended Papers from Science and Information Conference 2014

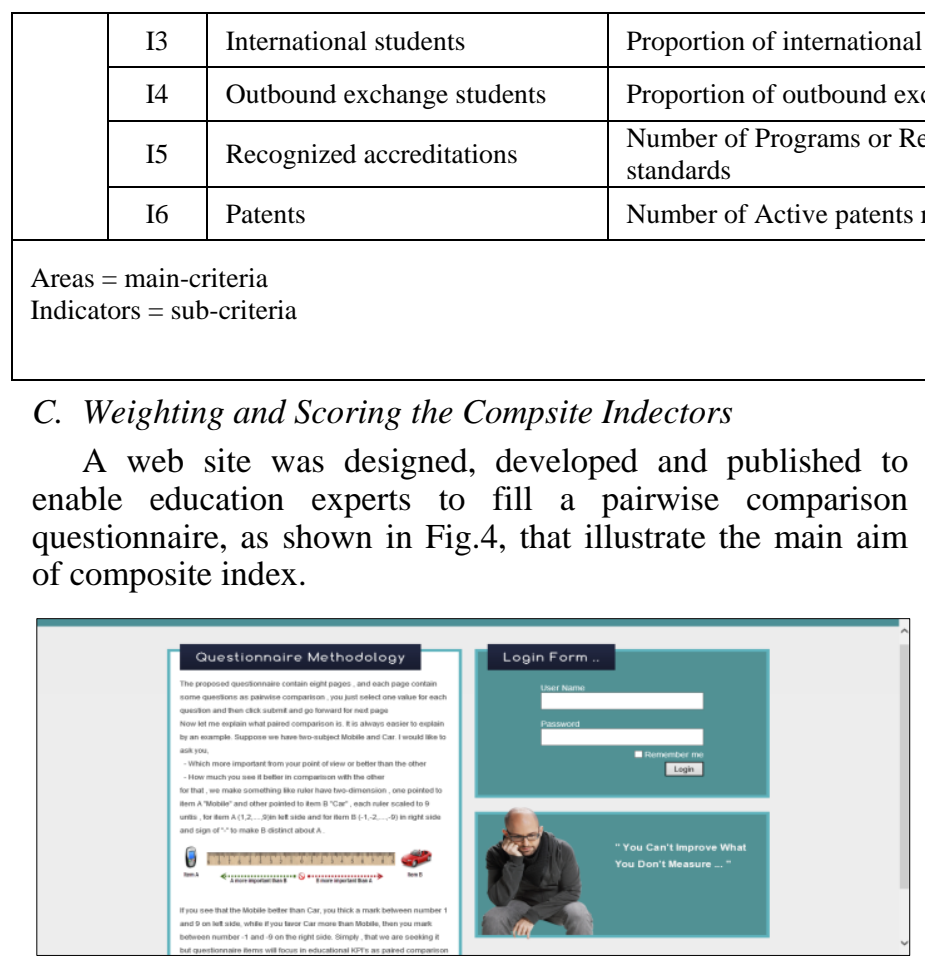

Fig. 4. The proposed website for data collection

The questionnaire has 90 pairwise comparison questions express hierarchical structure combination between maincriteria as main areas of KPIs , and sub-criteria as common set of performance indicators that used in higher education performance measurement, as shown earlier in Fig.3.

These indicators were classified on the basis of business functions to: (1) students indictors; (2) faculties indictors; (3) teaching \& learning indictors; (4) research indictors; (5) students support indictors; (6) reputation indictors; and (7) internationalization indictors. The GUI shown in Fig.5 displays a part of pairwise comparison questions for a set of key performance indicators related to students support area.

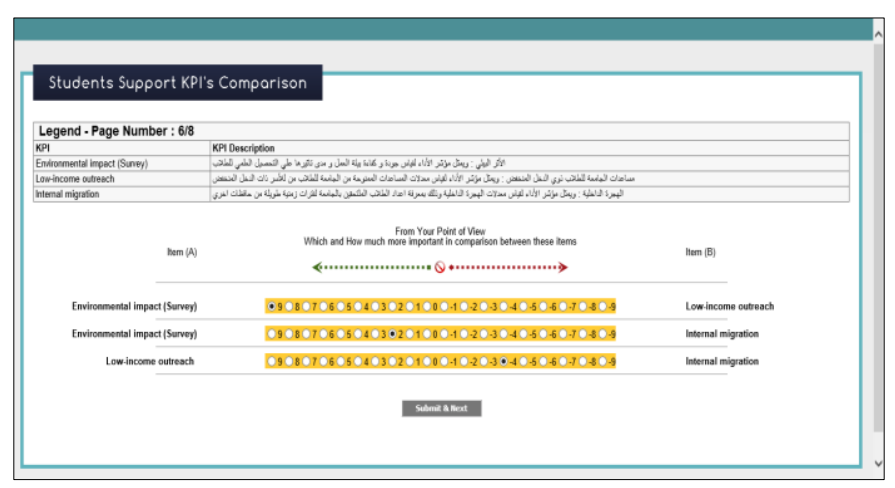

Fig. 5. Simple pairwise comparison page

Each question represented as two-dimensional ruler to identify importance of pairwise, as shown in Fig.6, importance selection based on evaluation scale defined in Table II.

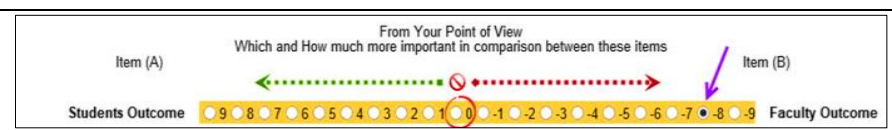

Fig. 6. Simple of question as two-dimensional ruler

One-to-one comparisons of factors correlatively, which is the second stage, the 1-9 evaluation-scale used is shown in Table II. The results of questionnaire survey given by the universities' professors in accordance with the evaluation scale are translated into pairwise comparison matrix then calculated in order to obtain geometric mean using the row geometric mean method (RGMM), and then to start weighting process.

In order to count the number of comparisons for combination of sixteen KPIs grouped in seven areas, can be represented as:

$$
\frac{\mathrm{n}(\mathrm{n}-1)}{2}+\left\{\sum_{i=1}^{\mathrm{n}} \mathrm{m}(\mathrm{m}-1) / 2\right\} \quad \mathrm{m}, \mathrm{n}>0
$$

Where $n=$ number of main-criteria's items (KPIs Areas) and $m=$ number of sub-criteria's (KPIs list that categorized under area).

$$
=\frac{7(7-1)}{2}+\left\{\frac{30+12+42+12+6+6+30}{2}\right\}=90
$$

This number reflects the total number of all pairwise comparisons rows and questionnaire questions, while the number of pairwise comparisons per each iteration for comparison matrix, can be represented as $=1+n=1+7=8$. For each iteration, number of comparisons is $n(n-1) / 2$.

The Aggregation of Individual Judgments (AIJ) [25] technique used in this case study. For the consolidated decision matrix $\mathrm{Z}$ that combines all $\mathrm{k}$ participants' inputs to get the aggregated group comparative matrix (judgment matrix), the weighted geometric mean method (WGMM) of the decision matrices attribute $\mathrm{rij}(\mathrm{k})$ using the individual decision maker's weight $\mathrm{wk}_{\mathrm{k}}$ as given,

$$
Z i j=\exp \frac{\sum_{k=1}^{M} w k \ln \operatorname{rij}(\mathrm{k})}{\sum_{k=1}^{M} w k}
$$

The pairwise comparison of attribute $i$ with attribute $\mathrm{j}$ yields a square matrix $\mathrm{AM} \times \mathrm{M}$ for $\mathrm{M}$ attributes where $\mathrm{r}_{\mathrm{ij}}$ denotes the comparative importance of attribute $i$ with respect to attribute $\mathrm{j}$. In the matrix, $\mathrm{r}_{\mathrm{ij}}=1$ when $\mathrm{i}=\mathrm{j}$ and $\mathrm{r}_{\mathrm{ji}}=1 / \mathrm{r}_{\mathrm{ij}}$. 


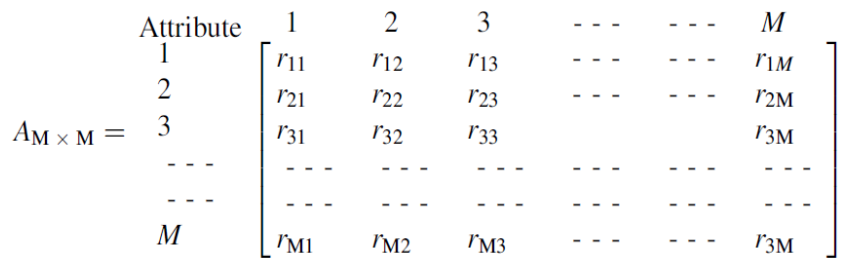

The relative normalized weight $\left(\mathrm{wj}_{\mathrm{j}}\right)$ of each attribute founded by (1) calculating the geometric mean of $i^{\text {th }}$ row, this can be represented as,

$$
\mathrm{GM}_{j}=\left\{\prod_{j=1}^{\mathrm{M}} \mathrm{r}_{\mathrm{ij}}\right\}^{1=\mathrm{M}}
$$

The row geometric mean method (RGMM) [25] is used to find out the relative normalized weights of the attributes to find out the maximum Eigen value easily and to reduce the inconsistency in judgments; and (2) normalizing the geometric means of rows in the comparison matrix, this represented as follow,

$$
\mathrm{w}_{j}=\mathrm{GM}_{j} / \sum_{\mathrm{j}=1}^{\mathrm{M}} \mathrm{GM}_{j}
$$

The normalization process performed hereby and determination of significance levels are the third stage. Since the relative importance of different indicators is compared and judged, the fourth stage started because the personal error existed makes the consistency test necessary to make sure if the calculated weight vector value is scientific and rational. The maximum eigenvalue of the judgment matrix calculated as follow,

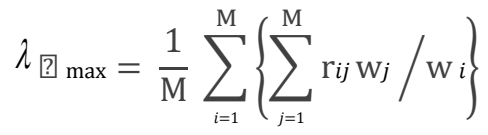

The value of consistency index (CI) obtained from below formula, the smaller of $\mathrm{CI}$ is the deviation from the consistency,

$$
\mathrm{CI}=\frac{\left(\lambda_{\max }-\mathrm{M}\right)}{(\mathrm{M}-1)}
$$

The random index (RI) for the number of attributes used in decision making. Table IV presents the RI values for different number of attributes.

TABLE IV. RANDOM INDEX (RI) VALUES

\begin{tabular}{llllllllllllllll}
\hline$n$ & 1 & 2 & 3 & 4 & 5 & 6 & 7 & 8 & 9 & 10 & 11 & 12 & 13 & 14 & 15 \\
\hline RI & 0 & 0 & 0.52 & 0.89 & 1.11 & 1.25 & 1.35 & 1.4 & 1.45 & 1.49 & 1.51 & 1.54 & 1.56 & 1.57 & 1.59 \\
\hline
\end{tabular}

The consistency ratio (CR) calculated to consider the acceptance of the study and it reflects an informed judgment that could be attributed to the knowledge of this case when the value of CR less than 0.1 or equal. Usually, the consistency ratio the ratio of $\mathrm{CI}$ and $\mathrm{RI}$, represented as follow,

$$
\mathrm{CR}=\mathrm{CI} / \mathrm{RI}
$$

In 2006, Alonso and Lamata have computed a regression of the random indices and propose the formulation [27]:

$$
\mathrm{CR}=\frac{\lambda_{\max }-\mathrm{M}}{(2.7699 \mathrm{M}-4.3513)-\mathrm{M}}
$$

In this case study, Alonson, Lamata used to fit resulting of consistency ratio. The Geometric Consistency Index (GCI) also, used to measure consistency, GCI have been developed in order to discover contradictory judgments, the value of GCI $=0.3147$ for $\mathrm{M}=3, \mathrm{GCI}=0.3526$ for $\mathrm{M}=4$ and $\mathrm{GCI}=0.370$ for $M>4$ will be accepted based on Aguarón and MorenoJiménez determination [28], and it is calculated using:

$$
\mathrm{GCI}=\frac{2 \sum_{i<j} \ln r_{i j}-\ln \frac{\mathrm{W}_{\mathrm{i}}}{\mathrm{W}_{\mathrm{j}}}}{(\mathrm{M}-1)(\mathrm{M}-2)}
$$

The fifth stage in implementation, the overall or composite performance scores for the alternatives obtained by multiplying the relative normalized weight (wj) of each attribute with its corresponding normalized weight value for each alternative and making summation over all the attributes for each alternative.

$$
\mathrm{P}_{i}=\sum_{j=1}^{\mathrm{M}} \mathrm{w}_{j}\left(\mathrm{~m}_{i j}\right) \text { normal }
$$

Where $\left(\mathrm{m}_{\mathrm{ij}}\right)$ normal represents the normalized value of (mij). Pi is the overall or composite score of the alternative Ai. The alternative with the highest value of $\mathrm{Pi}$ is considered as the best alternative. Based on the methodology and hierarchical structure in this section, there are 8 pair-wise comparison matrices evaluated by 40 professors from 19 renowned universities in Egypt, in addition, they are responsible about Education System development in ICTP project as MIS managers in their universities. The group comparative matrix for the main criteria, as show in Table V, its analysis illustrated as following,

TABLE V. THE Group COMPARATIVE MATRIX For THE MAIN CRITERIA

$\left(\begin{array}{ccccccc}1 & 14 / 5 & 2 / 5 & 2 / 5 & 1 & 21 / 8 & 2 / 3 \\ 5 / 9 & 1 & 1 / 4 & 1 / 3 & 3 / 4 & 14 / 9 & 8 / 9 \\ 23 / 5 & 32 / 3 & 1 & 1 & 2 & 14 / 5 & 13 / 7 \\ 21 / 2 & 31 / 5 & 11 / 9 & 1 & 11 / 2 & 21 / 2 & 14 / 9 \\ 1 & 13 / 8 & 1 / 2 & 2 / 3 & 1 & 13 / 8 & 11 / 5 \\ 1 / 2 & 2 / 3 & 5 / 9 & 2 / 5 & 3 / 4 & 1 & 7 / 8 \\ 11 / 2 & 11 / 8 & 5 / 7 & 2 / 3 & 5 / 6 & 11 / 7 & 1\end{array}\right)$

The relative normalized weight obtained using Eq. (3) and Eq. (4), w1 $=0.118, \quad w 2=0.085, \quad w 3=0.229, \quad w 4=0.228$, $\mathrm{w} 5=0.125, \mathrm{w} 6=0.087, \mathrm{w} 7=0.0 .128$, the maximum Eigen value $\lambda_{\text {๑max }}$ computed from Eq.(5), Lambda(max) $=7.186$, and consistency index $\mathrm{CI}=0.031$ from Eq.(6) as shown in same figure, the consistency ratio where random index (RI) of 7 attributes $=1.35,(\mathrm{CR})$ value is 0.023 , and GCI is 0.09 , by these consistency values, we claims that the feedbacks of the education expertise and decision makers are consistent. After the normalization process in the main-criteria which are seven performance indicators' significance levels are calculated according to the higher education experts. The most important indicators for them in higher education sector have been 
identified as teaching \& learning indicators, according to the findings teaching \& learning indicators have $(22.9 \%)$, research indicators have $(22.8 \%)$, internationalization indicators have $(12.8 \%)$, students support indicators have (12.5\%), student's indicators have $(11.8 \%)$, reputation indicators have $(8.7 \%)$, and faculty outcomes have $(8.5 \%)$ importance as shown in Fig. 10.

\begin{tabular}{|c|c|c|c|c|}
\hline Table & Criterion & Comment & Weights & Rk \\
\hline & 1 Students Outcom & Set of indicators that measure the performance of students and student & $11.8 \%$ & 5 \\
\hline & 2 Faculty Outcome & Set of indicators that measure the performance of faculty and faculty ou & $8.5 \%$ & 7 \\
\hline & 3 Teaching \& Learn & Set of indicators that measure the performance of teaching \& learning & $22.9 \%$ & 1 \\
\hline & 4 Reserch & Set of indicators that measure the performance of academic reserch of & $22.8 \%$ & 2 \\
\hline & 5 Students Suppor & Set of indicators that measure the performance of university that take ca & $12.5 \%$ & 4 \\
\hline & 6 Reputation & Outside influences that can impact in university ranking, measured by $s$ & $8.7 \%$ & 6 \\
\hline & 7 Internationalisatid & Set of indicators that measure the performance of university from interns & $12.8 \%$ & 3 \\
\hline Result & Eigenvalue & lambda: & & \\
\hline & Consistency Rati & 0.37 GC: 0.09 & & \\
\hline
\end{tabular}

Fig. 10. Analysis and results of main-criteria (indictor's area)

The aggregated group comparative matrix of others levels and iterations calculated and tested in the same way.

\section{EXPERIMENTAL RESULTS}

After comparison of main-criteria, comparisons and normalizations of performance indicators that are sub-criteria have been carried out. The second, the third and the fourth stages of AHP are repeated herein respectively. Teaching \& learning indicators based on sub-criteria in Fig.11, and significance levels calculated after normalization are shown.

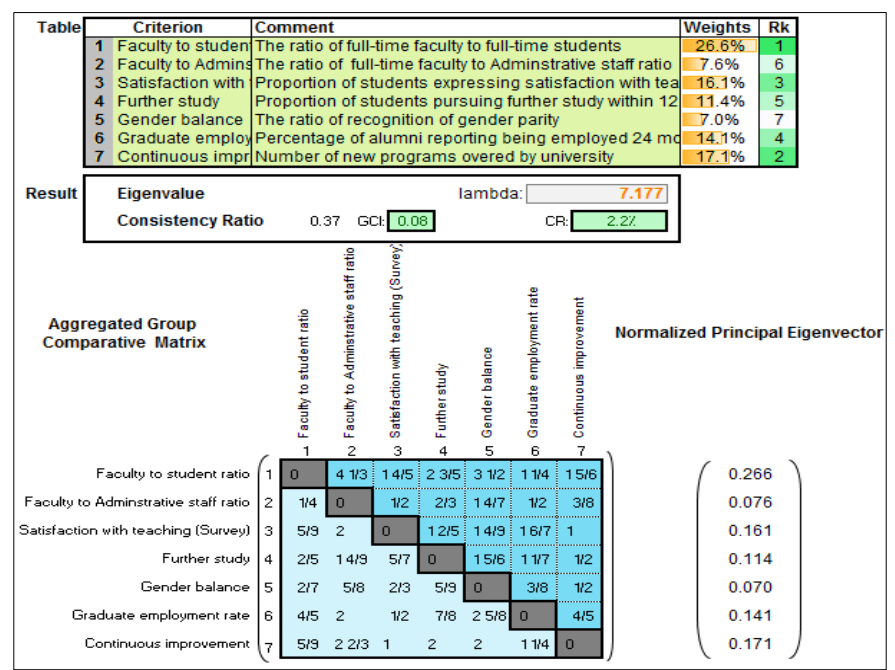

Fig. 11. Analysis and results of teaching \& learning indicators

Fig.11 determines the significance levels of 7 teaching \& learning indicators among themselves and present aggregated group judgment matrix of these sub-criteria. The significance levels of teaching \& learning indicators are; faculty to student ratio $(26 \%)$; continuous improvement (17.1\%); satisfaction with teaching (survey) (16.1\%); graduate employment rate (14.1\%); further study (11.4\%); faculty to administrative staff ratio $(7.6 \%)$ and gender balance $(7 \%)$. The value of Lambda is 7.177, CR related to this matrix is 0.022 and GCI is 0.08 .
Fig.12 determines the significance levels of 4 research indicators among themselves and present aggregated group judgment matrix of these sub-criteria. The significance levels of research indicators are; research excellence and outputs $(35.9 \%)$; research funding $(27.5 \%)$; citations per paper $(19.3 \%)$ and papers per faculty $(17.1 \%)$. The value of Lambda is 4.025 , CR related to this matrix is 0.9 and GCI is 0.03 .

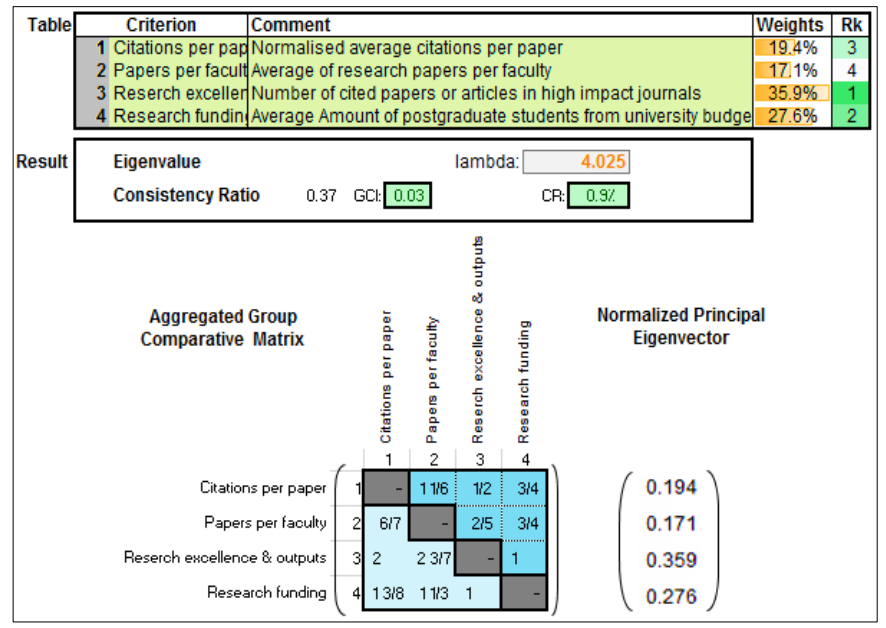

Fig. 12. Analysis and results of research indicators

Fig.13 determines the significance levels of 6 internationalization indicators among themselves and present aggregated group judgment matrix of these sub-criteria. The significance levels of internationalization indicators are; recognized accreditations (24.0\%); patents (23.5\%); international faculty (19.5\%); outbound exchange students (13.0\%); visiting scholars $(10.5 \%)$ and international students (9.5\%). The value of Lambda is 6.055 , CR related to this matrix is 0.09 and GCI is 0.03 .

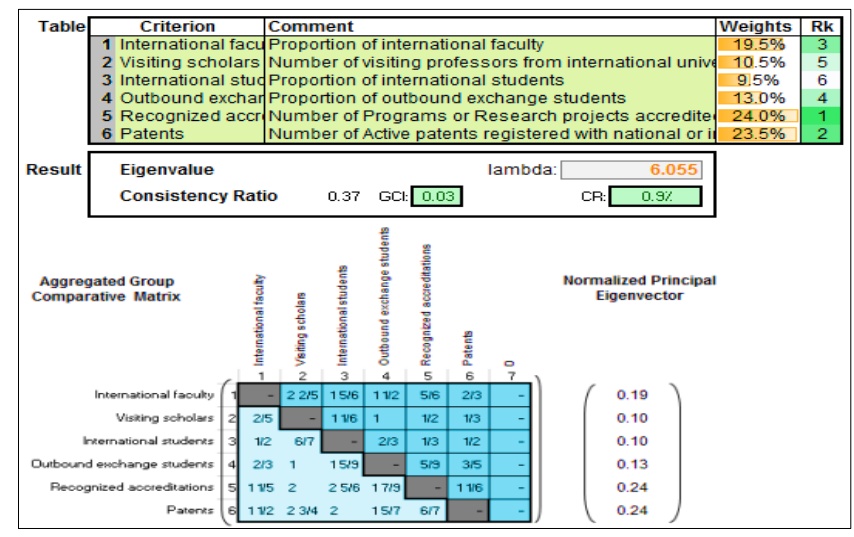

Fig. 13. Analysis and results of Internationalization indicators

Fig.14 determines the significance levels of 3 Students Support indicators among themselves and present aggregated group judgment matrix of these sub-criteria. The significance levels of students support indicators are; low-income outreach (48.0\%); environmental impact (survey) (33.3\%); and Internal migration $(18.7 \%)$. The value of Lambda is 3.046, CR related to this matrix is 0.048 and GCI is 0.14 . 


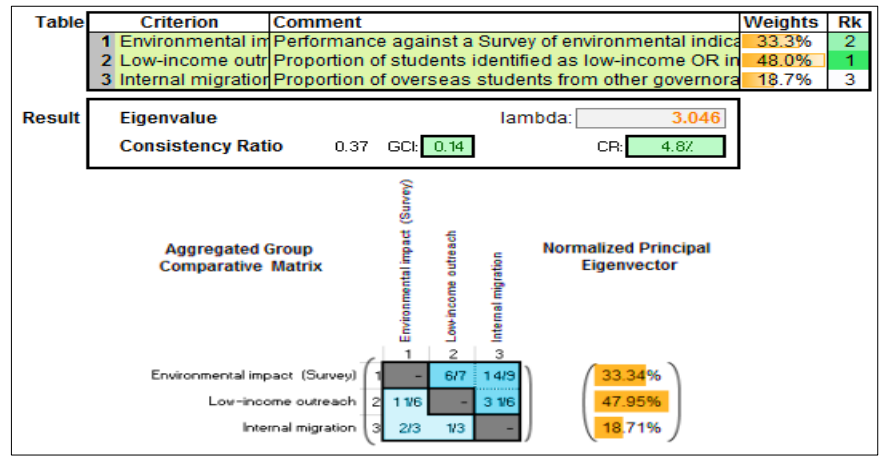

Fig. 14. Analysis and results of students support indicators

Fig.15 determines the significance levels of 6 student outcomes indicators among themselves and present aggregated group judgment matrix of these sub-criteria. The significance levels of student outcomes indicators are; participation (23.7\%); overall student satisfaction (survey) (18.7\%); completion (16.9\%); granted degrees $(16.4 \%)$; retention rate $(15.9 \%)$; and scholarships and bursaries $(8.4 \%)$. The value of Lambda is 6.173 , CR related to this matrix is 0.028 and $\mathrm{GCI}$ is 0.10 .

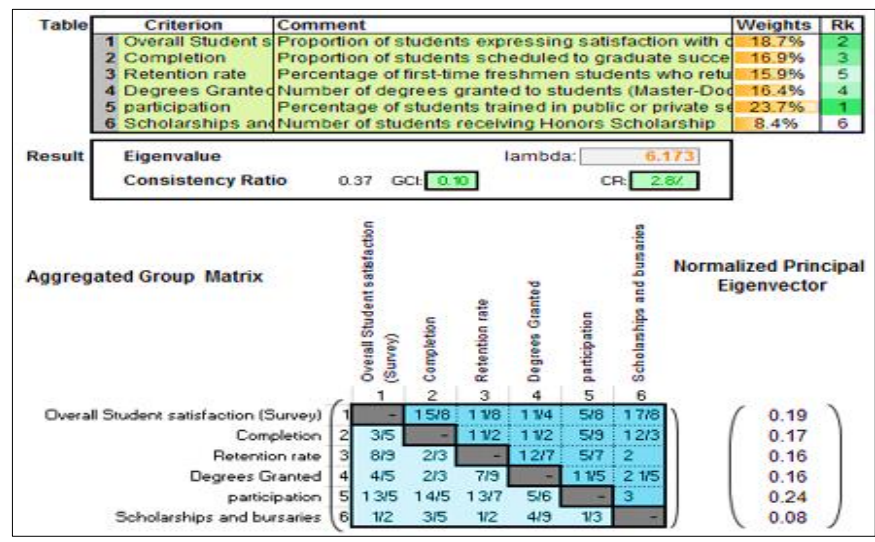

Fig. 15. Analysis and results of Student Outcomes indicators

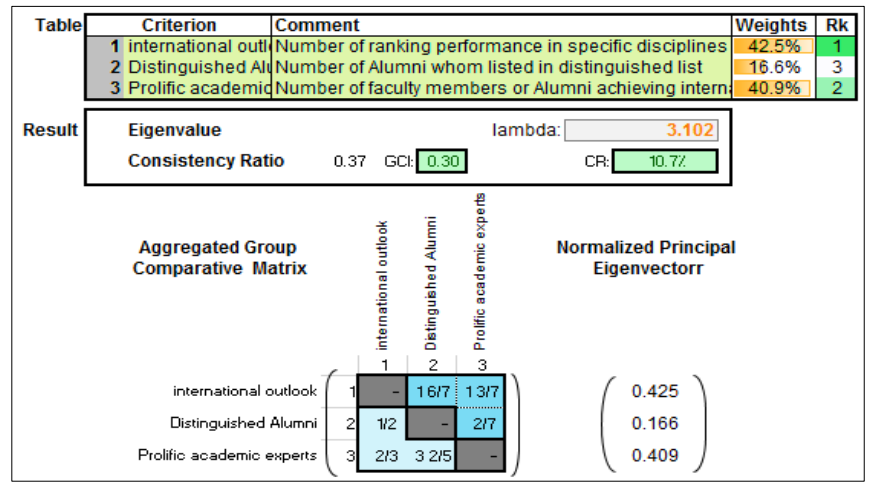

Fig. 16. Analysis and results of reputation indicators

Fig.16 determines the significance levels of 4 reputation indicators among themselves and present aggregated group judgment matrix of these sub-criteria. The significance levels of reputation indicators are; prolific academic experts (40.9\%); international outlook (45.0\%); and distinguished alumni
(16.6\%). The value of Lambda is 3.102, CR related to this matrix is 0.1 and GCI is 0.30 .

Fig.17 determines the significance levels of 4 faculty outcomes indicators among themselves and present aggregated group judgment matrix of these sub-criteria. The significance levels of faculty outcomes indicators are; efficiency (30.7\%); publications (24.2\%); faculty qualifications $(23.0 \%)$; and attainment $(22.1 \%)$. The value of Lambda is 4.289 , CR related to this matrix is 0.1 and GCI is 0.37 .

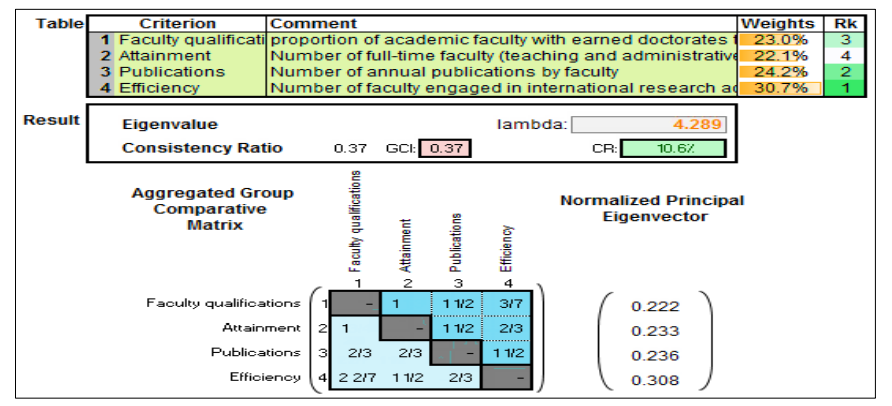

Fig. 17. Analysis and results of faculty outcomes indicators

According to obtained results; in total 33 performance indicators, 7 of which are teaching \& learning indicators, 4 research indicators, 6 internationalization indicators, 3 students support indicators, 6 students outcomes indicators, 3 reputation indicators and 4 faculty outcomes indicators, a set of common performance indicators has been built. In the set, the significance level that is a basis to measuring the performance of higher education in Egypt has been designated as well. As a result of product for significance levels related to main and sub-criteria, priorities that are the last stage of AHP have been ascertained to obtain the overall or composite performance using Eq. (10). Table VI is formed in order to understand and apply the set of performance indicators that can be used by the proposed composite index. This table also presents the significance level of each performance indicator per over all sub-criteria. In the indicator Area and weight of area columns in Table VI are 7 indicators areas for higher education systems, KPI's and weights of which are measured and presented in Fig.10. Indicator column represents the performance indicators present in each indicator area on the basis of codes defined in Table III. Weight of type column includes the significance levels all sub-criteria of each KPI. Data Source column represents on which solution or application system can be defined as data source for this kind of KPI or external data source if required. Direction of expectation (DoE) column represents on which direction an expectation, up or down, should occur about the related indicator. Unit of measurement column, explains the unit of value to be obtained by the calculation on the related indicator. Value of weight column is about determining the priorities present in the last stage of AHP. Value weight is obtained by the multiplication of the main criteria and sub-criteria weights. For example, value of weight is obtained by main criteria weight (weight in area of students' outcomes area) * subcriteria weight (weight in type of retention rate indictor) formulization. $0.118 * 0.159=0.0188=1.88 \%$. This calculation is made for 33 performance indicators. 
To build the full solution that helps decision makers of higher education in Egypt and domain experts in each university, we have built full integrated solution based-on business intelligence (BI) using Data Warehouse (DW) concepts that will collect required data from Universities Management Information Systems (MIS) as step to extract and calculate required information for the proposed framework.

There are two different database schemes for MIS solutions hosted in universities of Egypt, first scheme related to universities that teaching by Traditional Education System (TES) or Balk Courses Registration (BCR), and other scheme, for institutes that teaching by Credit-Hours Education System (CHES). For that staging database was developed to obtained raw data. Once the data is in the staging area, we encounter staging metadata to guide the transformation and loading processes, including staging file and target table layouts, transformation and cleansing rules, conformed dimension and fact definitions, aggregation definitions, and ETL transmission schedules and run-log results. Moreover, a prototype has been implemented to apply the proposed model and apply comparative analysis using proposed framework, universities in the prototype, anonymously identified as university A, B, C and $\mathrm{D}$ as show in Table. VI

TABLE VI. UNVERSTIEIS THAT INVLOVED IN PROTOTYPE

\begin{tabular}{|l|l|l|l|l|l|}
\hline & Scale & $\begin{array}{l}\text { Enrolled } \\
\text { Students }\end{array}$ & $\begin{array}{l}\text { Graduate } \\
\text { Students }\end{array}$ & $\begin{array}{l}\text { Admitted } \\
\text { Students }\end{array}$ & GRS* \\
\hline University A & Large & $\sim 140 \mathrm{k}$ & $\sim 38 \mathrm{k}$ & $\sim 34 \mathrm{k}$ & Yes \\
\hline University B & Large & $\sim 130 \mathrm{k}$ & $\sim 33 \mathrm{k}$ & $\sim 33 \mathrm{k}$ & No \\
\hline University C & Medium & $\sim 50 \mathrm{k}$ & $\sim 15 \mathrm{k}$ & $\sim 17 \mathrm{k}$ & No \\
\hline University D & Small & $\sim 19 \mathrm{k}$ & $\sim 5 \mathrm{k}$ & $\sim 4 \mathrm{k}$ & Yes \\
\hline
\end{tabular}

* State of university that appears in global ranking system

Aggregation method entails the calculation of the ranking of each university according to each individual indicator, e.g. to apply required aggregation method for Granted Degrees indictor under student's outcomes indecator area, we are used Multi-Year Growth Rate Method (MYGRM) to calaculacte this indcator for five acadamic year, by this we can achive Time phased element of SMART cirtira to devlope indictors and to calculate the value of each university for five years, the below steps followed as show in Fig.18 and Fig.21.

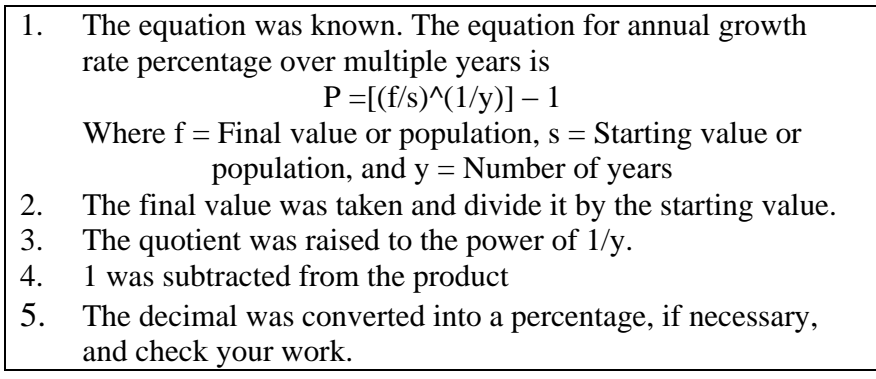

Fig. 18. Steps followed to calculate Aggregation of Granted Degree indictor

Since the all indictor's data aggregated the role of data normalization raised, it is required prior to any data aggregation as the indicators in a data set often have different measurement units, and the normalization methods used in our model show in Table. VII

TABLE VII. NORMaLIZATION METHOdS USED IN PROPOSED FRAMWORK

\begin{tabular}{ll}
\hline \multicolumn{1}{c}{ Method } & \multicolumn{1}{c}{ Equation } \\
\hline 1. Ranking & $I_{q c}^{t}=\operatorname{Rank}\left(x_{q c}^{t}\right)$ \\
\hline 2. Standardisation (or Z-scores) & $I_{q c}^{t}=\frac{x_{q c}^{t}-x_{q c=\bar{c}}^{t}}{\sigma_{q c \bar{c}}^{t}}$ \\
\hline 3. Min-Max & $I_{q c}^{t}=\frac{x_{q c}^{t}-\min _{c}\left(x_{q}^{t_{0}}\right)}{\max _{c}\left(x_{q}^{t}\right)-\min _{c}\left(x_{q}^{t_{0}}\right)}$. \\
\hline $\begin{array}{l}\text { 4. Percentage of annual differences over } \\
\text { consecutive years }\end{array}$ & $I_{q c}^{t}=\frac{x_{q c}^{t}-x_{q c}^{t-1}}{x_{q c}^{t}}$ \\
\hline
\end{tabular}

The normalized and summarized data are maintained in the marts and are organized in a star schema to provide a dimensional view of the data, a dynamic and interactive dashboard with four views were implemented to simulate the composite index functions and represent visual interface for outcomes of campsite index as following, (1) Measures View Dashboard; (2) Indicators View Dashboard; (3) Index View Dashboard; and (4) League View Dashboard, as show in in Fig.19

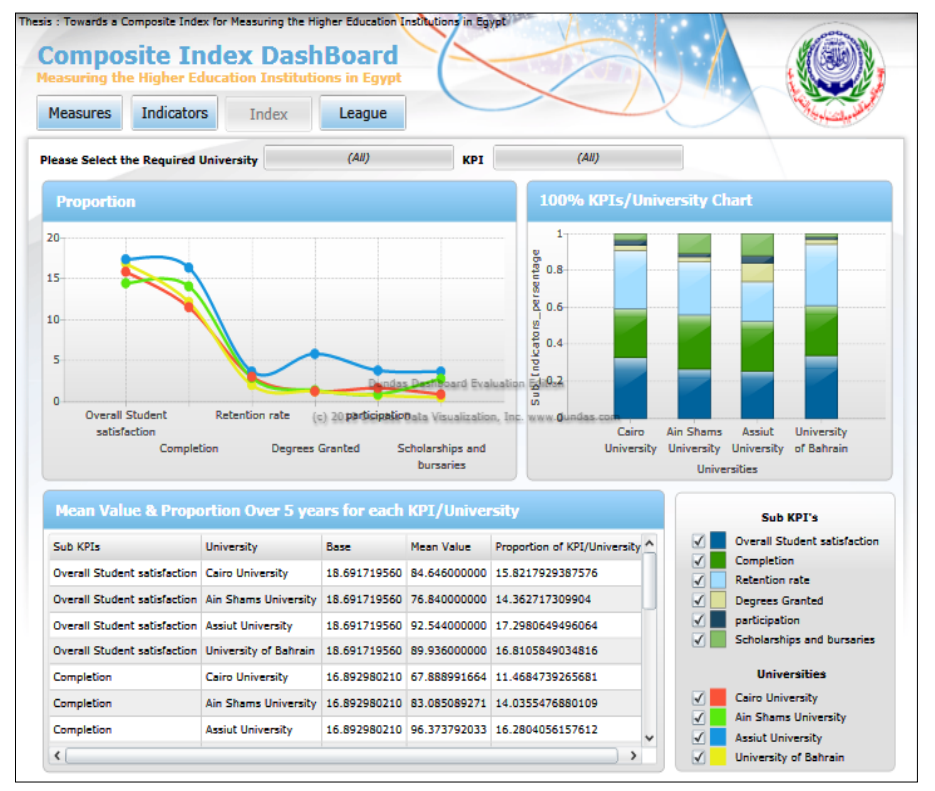

Fig. 19. Visual Dashboard of Composite Index

As show in Fig.20, the university $\mathrm{C}$ ranked as top university, university A ranked as third university. Meanwhile, the university A appears in several Global Ranking Systems. By this we can prove that university $\mathrm{C}$ should appears also into Global Ranking Systems but there are some reasons prevented the appearance, and we can conclude these issues as following; (1) related to cut-off, stop displaying university scores after certain rank; (2) related to target audience; (3) related to design and objective; (4) Not aim to label or focuson Egyptian universities; (5) May lead to redesigning of strategy to improve in the rankings rather than to do what's right for the local setting; and (5)sources of information not exhaustive. 


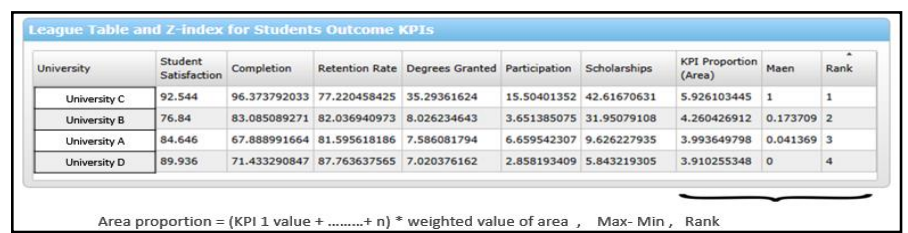

Fig. 20. Composite Index League Table

\section{CONCLUSION}

In this paper, we proposed a unified and unique composite index for higher education institutions in Egypt aims to, (1) benchmark the overall performance and support selfassessment; (2) transform organizational processes into strategic tools, helping higher education institutions to compare systematically their practice and performance with peer institutions; (3) periodical performance mentoring tool; (4) obtain data to support decision-making; (5) measure performance against and compare with other institutions and assess reasons for any deviations; (6) focus on how the improvement or retracement done rather than who is best; (7) encourage discovery of new ideas through a strategic look inside or outside the institution; (8) follow and set new standards for the institution and higher education system; (9) respond to international benchmarks and performance indicators; (10) set effective targets to achieve accreditation, quality assurance improvement and evaluation processes; and (11) enhance reputation and build new brand for Egyptian case.

Indeed, decision maker and institutes' leaders are forced to make their decisions transparent and comprehensible and draw attention to major issues. The proposed composite index established dependent on the framework [20,21] than on methodological choices as ranking system, this will make idea of this research usable and can be published.

The AHP algorithm and dynamic dashboard assists our objective judgment and makes the research results more comprehensive and reasonable depending on participation of universities professors as education experts from 19 renowned universities in Egypt. The weights of KPI areas of the proposed composite index belong to the Egyptian situation are summarized into, teaching \& learning indicators have (22.9\%), research indicators have $(22.8 \%)$, internationalization indicators have $(12.8 \%)$, students support indicators have $(12.5 \%)$, student's indicators have $(11.8 \%)$, reputation indicators have $(8.7 \%)$, and faculty outcomes have $(8.5 \%)$ importance, as green-to-red scale that shown in table VI. And for sub-criteria, the most important indicators have been identified as research excellence \& outputs $(8.19 \%)$ under research indicators area, then Faculty to student ratio (6.1\%) under facilities indicators area. No index can be better without; (1) data feeds from different data sources; and (2) using of trends and outcomes as results of this index. For that in the future work, we aims to collect required data from different data sources of higher education institutions in Egypt, for example, MIS and LMS application on each university and linking with other external data sources .

Moreover, enhancement phase of composite index lifecycle will be implemented as feature work and an interactive dashboard will designed to visualize outcomes of composite index, this will assists our work and place powerful way to track universities' performance and reaching their overall goal.

\section{ACKNOWLEDGMENT}

The authors would like to acknowledge the support done by the Ministry of Higher Education - Information and Communications Technology Project (ICTP) especially MIS Team.

\section{REFERENCES}

[1] (2013) Human Development Index - Annual Report 2013 [Online]. Available: http://hdr.undp.org/en/countries/profiles/EGY

[2] (2013) Supreme Council of Universities - Egypt strategy plan for education until 2021 [Online]. Available: http://mhe-spu.org/siteold/admin/uploads/events/files/Report_on_Master_Plan.pdf

[3] M. El-Hadidi, H. Anis, S. El-Akabawi, A. Fahmy, M. Salem, A. Tantawy, A. El-Rafie, M. Saleh, T. El-Ahmady, I. Abdel-Moniem, A. Hassan, A. Saad, H. Fahim, T. Gharib, M. Sharawy and K. AbdelFattah, "Quantifying the ICT Needs of Academic Institutes Using the Service Category-Stakeholder Matrix Approach," $6^{\text {th }}$ ICICT'08 Conference Proc, December 2008, pp. 107-113.

[4] (2012) Information and Communications Technology Project, unified Management Information System brief description [Online]. Available: http://www.ictp.org.eg/index.php/ar/2012-11-03-22-55-31/2012-11-0322-56-46

[5] Liu, Nian Cai, Qi Wang, and Ying Cheng, eds. Paths to a world-class university: Lessons from practices and experiences. Vol. 23. Springer, 2011.

[6] Alexander, F. King. "The changing face of accountability: Monitoring and assessing institutional performance in higher education." Journal of Higher Education (2000): 411-43.

[7] McKinnon, K. R., S. H. Walker, and D. Davis. "A manual for Australian Universities." Australian Higher Education Division, Australia (2000).

[8] Sadlak, Jan, and Nian Cai Liu. The world-class university and ranking: Aiming beyond status. Bucharest, Romania/Shanghai, China/ClujNapoca, Romania: Unesco-Cepes, 2007.

[9] Hazelkorn, Ellen. "How Rankings are Reshaping Higher Education." (2013).

[10] Rauhvargers, Andrejs. "Global university rankings and their impact" Leadership for WorldClass Universities Challenges for Developing Countries June (2011).

[11] Zhou, P., B. W. Ang, and D. Q. Zhou. "Weighting and aggregation in composite indicator construction: a multiplicative optimization approach." Social Indicators Research 96, no. 1 (2010): 169-181.

[12] Ismail, Engr Muhammad. "Ranking of universities." In 2nd International Conference on Assessing Quality in Higher Education, pp. 6-8. 2010.

[13] Saaty, T. L. (1988). What is the analytic hierarchy process? (pp. 109121). Springer Berlin Heidelberg.

[14] Lingxi, Zhu, and Yu Hao. "Study on the AHP-based evaluation system of excellence of university classes." In Education and Management Technology (ICEMT), 2010 International Conference on, pp. 242-247. IEEE, 2010.

[15] Badri, Masood A., and Mohammed H. Abdulla. "Awards of excellence in institutions of higher education: an AHP approach." International Journal of Educational Management 18, no. 4 (2004): 224-242.

[16] Lavy, Victor. "Evaluating the effect of teachers' group performance incentives on pupil achievement." Journal of political Economy 110, no. 6 (2002): 1286-1317.

[17] Saltelli, Andrea. "Composite indicators between analysis and advocacy." Social Indicators Research 81, no. 1 (2007): 65-77.

[18] Bandura, Romina. "A survey of composite indices measuring country performance: 2008 update." Office of Development Studies, New York: United Nations Development Program (2008).

[19] Giovannini, Enrico, Michela Nardo, Michaela Saisana, Andrea Saltelli, A. Tarantola, and Anders Hoffman. Handbook on constructing 
composite indicators: methodology and user guide. Organisation for Economic Cooperation and Development (OECD), 2008

[20] Saisana, Michaela, Béatrice d'Hombres, and Andrea Saltelli. "Rickety numbers: Volatility of university rankings and policy implications." Research Policy 40, no. 1 (2011): 165-177.

[21] Paruolo, Paolo, Michaela Saisana, and Andrea Saltelli. "Ratings and rankings: voodoo or science?." Journal of the Royal Statistical Society: Series A (Statistics in Society) (2012).

[22] Saaty, Thomas L., and Luis G. VARGAS. "Fundamentals of Decision Making and Priority Theory with the Analytic Hierarchy Process. The Analytic Hierarchy Process, vol. 6." (2000).

[23] Eccles, Charles. "The use of university rankings in the United Kingdom." Higher Education in Europe 27, no. 4 (2002): 423-432

[24] XU, Qian, Wen-lei QU, and Fang-chun QIU. "The design for the index system of college teachers performance assessment based on the AHP method [J]." Journal of Qingdao University of Science and Technology (Social Sciences) 4 (2008): 021.
[25] Forman, Ernest, and Kirti Peniwati. "Aggregating individual judgments and priorities with the analytic hierarchy process." European Journal of Operational Research 108, no. 1 (1998): 165-169.

[26] Escobar, María Teresa, and José María Moreno-jiménez. "Aggregation of individual preference structures in AHP-group decision making." Group Decision and Negotiation 16, no. 4 (2007): 287-301.

[27] Alonso, Jose Antonio, and M. Teresa Lamata. "Consistency in the analytic hierarchy process: a new approach." International Journal of Uncertainty, Fuzziness and Knowledge-Based Systems 14, no. 04 (2006): 445-459.

[28] Aguaron, Juan, and José María Moreno-Jiménez. "The geometric consistency index: Approximated thresholds." European Journal of Operational Research 147, no. 1 (2003): 137-145.

[29] Mohamed Rashad M Elhefnawy, Ali El-Bastawissy, Mona Kadry (August, 2014). "Towards a Composite Index for Measuring the Higher Education Institutions in Egypt. "Science and Information Conference (SAI), London, 2014, pp. 31-41. IEEE, 2014.

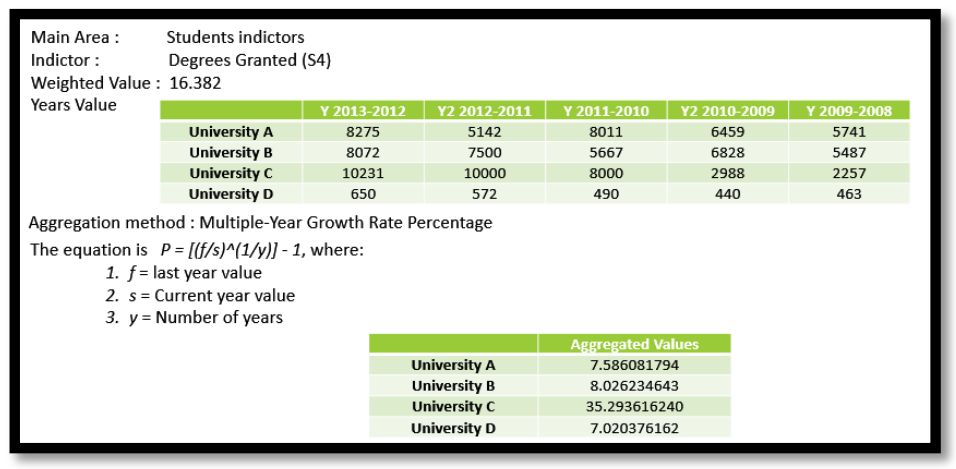

Fig. 21. Aggregation simple for Granted Degree indictor

TABLE VIII. Full COMPOSITE PERFormanCE SCORES For COMPOSITE INDEX FraMework

\begin{tabular}{|c|c|c|c|c|c|c|c|c|c|}
\hline$\#$ & Area & $\begin{array}{c}\text { Weight of } \\
\text { Area (\%) }\end{array}$ & Code & $\begin{array}{c}\text { Weight In } \\
\text { Type (\%) } \\
\end{array}$ & Indicator & Data Source & DoE & $\begin{array}{c}\text { Unit of } \\
\text { Measurement }\end{array}$ & $\begin{array}{c}\text { Value of } \\
\text { Weight (\%) }\end{array}$ \\
\hline 1 & \multirow{6}{*}{ Students Outcome } & \multirow{6}{*}{$11.80 \%$} & S1 & $18.69 \%$ & Overall Student satisfaction (Survey) & Survey DB & 푼 & Per Cent & $2.21 \%$ \\
\hline 2 & & & S2 & $16.89 \%$ & Completion & MIS DB & r & Per Cent & $1.99 \%$ \\
\hline 3 & & & S3 & $15.95 \%$ & Retention rate & MIS DB & $y$ & Per Cent & $1.88 \%$ \\
\hline 4 & & & 54 & $16.38 \%$ & Degrees Granted & MIS DB & 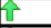 & Count & $1.93 \%$ \\
\hline 5 & & & S5 & $23.73 \%$ & participation & MIS DB & ب & Per Cent & $2.80 \%$ \\
\hline 6 & & & 56 & $8 \quad 8.36 \%$ & Scholarships and bursaries & MIS DB & r & Count & $0.99 \%$ \\
\hline 7 & \multirow{4}{*}{ Faculty Outcome } & \multirow{4}{*}{$8.54 \%$} & F1 & $\nabla \quad 22.20 \%$ & \begin{tabular}{|l|} 
Faculty qualifications \\
\end{tabular} & MIS DB & ب & Per Cent & $1.90 \%$ \\
\hline 8 & & & F2 & $\nabla \quad 23.34 \%$ & Attainment & MIS DB & ب & Count & $1.99 \%$ \\
\hline 9 & & & $\mathrm{F3}$ & $23.62 \%$ & Publications & MIS DB & & Count & $2.02 \%$ \\
\hline 10 & & & $\mathrm{~F} 4$ & $30.84 \%$ & Efficiency & MIS DB & r & Count & $2.63 \%$ \\
\hline 11 & \multirow{7}{*}{ Teaching \& Learning } & \multirow{7}{*}{$22.91 \%$} & $\mathrm{~T} 1$ & $26.64 \%$ & Faculty to student ratio & MIS DB & 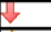 & Fraction & $6.10 \%$ \\
\hline 12 & & & $\mathrm{~T} 2$ & $\nabla \quad 7.58 \%$ & Faculty to Adminstrative staff ratio & MIS DB & $\Rightarrow$ & Fraction & $1.74 \%$ \\
\hline 13 & & & T3 & $16.12 \%$ & Satisfaction with teaching (Survey) & Survey DB & r & Per Cent & $3.69 \%$ \\
\hline 14 & & & T4 & $\nabla \quad 11.42 \%$ & Further study & MIS DB & r & Per Cent & $2.62 \%$ \\
\hline 15 & & & T5 & $\nabla \quad 7.04 \%$ & Gender balance & MIS DB & $\Rightarrow$ & Fraction & $1.61 \%$ \\
\hline 16 & & & T6 & $14.12 \%$ & Graduate employment rate & MIS DB & r & Per Cent & $3.24 \%$ \\
\hline 17 & & & $\mathrm{T7}$ & $17.08 \%$ & Continuous improvement & MIS DB & r & Count & $3.91 \%$ \\
\hline 18 & \multirow{4}{*}{ Reserch } & \multirow{4}{*}{$22.79 \%$} & R1 & \begin{tabular}{|l|}
$19.38 \%$ \\
\end{tabular} & Citations per paper & Extrnal DS & & Per Cent & $4.42 \%$ \\
\hline 19 & & & R2 & F $17.12 \%$ & Papers per faculty & MIS DB & ب & Per Cent & $3.90 \%$ \\
\hline 20 & & & R3 & $35.93 \%$ & Reserch excellence \& outputs & Extrnal DS & 눈 & Count & $8.19 \%$ \\
\hline 21 & & & R4 & $27.57 \%$ & Research funding & ERP DB & F & Per Cent & $6.28 \%$ \\
\hline 22 & \multirow{3}{*}{ Students Support } & \multirow{3}{*}{$12.49 \%$} & A1 & $33.34 \%$ & Environmental impact (Survey) & Survey DB & F & Per Cent & $4.16 \%$ \\
\hline 23 & & & $\mathrm{~A} 2$ & $477.95 \%$ & Low-income outreach & MIS DB & r & Per Cent & $5.99 \%$ \\
\hline 24 & & & $\mathrm{A3}$ & $\nabla \quad 18.71 \%$ & Internal migration & MIS DB & 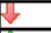 & Per Cent & $2.34 \%$ \\
\hline 25 & \multirow{3}{*}{ Reputation } & \multirow{3}{*}{$8.70 \%$} & E1 & $42.55 \%$ & international outlook & Extrnal DS & F & Count & $3.70 \%$ \\
\hline 26 & & & E2 & $\nabla \quad 16.58 \%$ & Distinguished Alumni & Extrnal DS & F & Count & $1.44 \%$ \\
\hline 27 & & & E3 & $40.88 \%$ & Prolific academic experts & Extrnal DS & F & Count & $3.55 \%$ \\
\hline 28 & \multirow{6}{*}{ Internationalisation } & \multirow{6}{*}{$12.77 \%$} & 11 & $19.47 \%$ & International faculty & MIS DB & F & Per Cent & $2.49 \%$ \\
\hline 29 & & & 12 & $\nabla \quad 10.46 \%$ & Visiting scholars & MIS DB & F & Count & $1.34 \%$ \\
\hline 30 & & & 13 & $\nabla \quad 9.54 \%$ & International students & MIS DB & F & Per Cent & $1.22 \%$ \\
\hline 31 & & & 14 & $\nabla \quad 13.00 \%$ & Outbound exchange students & MIS DB & 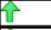 & Per Cent & $1.66 \%$ \\
\hline 32 & & & 15 & $24.00 \%$ & Recognized accreditations & MIS DB & 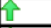 & Count & $3.06 \%$ \\
\hline 33 & & & 16 & $23.53 \%$ & Patents & MIS DB & tra & Count & $3.00 \%$ \\
\hline & Total $(\%)=$ & $100.00 \%$ & & & & & & Total $(\%)=$ & $100.00 \%$ \\
\hline
\end{tabular}

